\title{
Childhood Behavioral Inhibition and Maternal Symptoms of Depression
}

\author{
E. Moehler ${ }^{\mathrm{a}} \quad$ J. Kagan ${ }^{\mathrm{C}} \quad$ P. Parzer ${ }^{\mathrm{a}} \quad$ R. Brunner ${ }^{\mathrm{a}} \quad$ C. Reck ${ }^{\mathrm{b}} \quad$ A. Wiebel ${ }^{\mathrm{a}}$ \\ L. Poustka ${ }^{a}$ F. Resch ${ }^{a}$ \\ Departments of a Child and Adolescent Psychiatry and ${ }^{\mathrm{b}}$ Psychiatry, University of Heidelberg, Heidelberg, Germany; \\ 'Department of Psychology, Harvard University, Cambridge, Mass., USA
}

\section{Key Words}

Postpartum depression · Postnatal depression • Behavioral inhibition $\cdot$ Child development

\begin{abstract}
Background:The significance of behavioral inhibition in the second year of life for the development of social phobia in later childhood was the incentive to explore whether maternal postnatal psychopathology is a predictor for behavioral inhibition in the offspring. Method: 101 mother-infant pairs were recruited from local obstetric units and examined for maternal psychopathology by the Symptom Checklist and the Edinburgh Postnatal Depression Scale several times during the first postnatal year. Child behavioral inhibition was assessed at 14 months in a laboratory procedure. Results: Postpartum depression at 4 months measured by the Edinburgh Postnatal Depression Scale was found to be strongly associated with toddlers' fear score/behavioral inhibition at 14 months. Maternal depressive symptoms assessed by the revised 90-item Symptom Checklist at 6 weeks , 4 and 14 months were found to be related to child inhibition as well. Conclusions: Even maternal depression not reaching the level of clinical diagnosis and treatment has an impact on child behavioral development. These data should give rise to further studies on the origins of this relationship, which might be primarily genetic or interactional.
\end{abstract}

Copyright $\odot 2007$ S. Karger AG, Basel

\section{KARGER}

Fax +41613061234 E-Mail karger@karger.ch www.karger.com (c) 2007 S. Karger AG, Basel

0254-4962/07/0406-0446\$23.50/0

Accessible online at:

www.karger.com/psp

\section{Introduction}

Behavioral inhibition has been defined as a bias to respond to unfamiliar events with anxiety [1]. A body of evidence has emerged stating that extremely inhibited toddlers are likely to be inhibited with peers in later childhood $[2,3]$. Also, inhibited children at 14 months have been shown to more often show shy and withdrawn behavior at the age of 3 and 4 and have a higher rate of social anxiety at the age of 7.5 and social phobia in adolescence [4-6].

Fear or inhibition to unfamiliar events, people and stimuli at 14 months can therefore be regarded as an important predictor for child and adolescent emotional development. Extreme inhibition at 14 months seems to put the child at a severe risk for developing an internalizing disorder in later childhood [7].

To date, knowledge about the origins of these early and long-lasting behavioral differences is limited. A moderate association with specific sites on the glutamic acid decarboxylase gene has been shown to be linked to some degree to behavioral inhibition in mice [8]. Later a modest relation between an allele of the corticotropin-releasing-hormone-linked locus and behavioral inhibition was observed by the same authors [9].

Other findings support the view of behavioral inhibition as a dispositional trait: children with lower vagal tone tend to be more behaviorally inhibited [10]. Furthermore, the infant cardiac sympathetic tone at 6 weeks of age was found to predict behavioral inhibition as early as

Eva Moehler, MD

Department of Child and Adolescent Psychiatry, University of Heidelberg

Blumenstrasse 8, DE-69115 Heidelberg (Germany)

Tel. +496221563 9087, Fax +496221566941

E-Mail Eva_Moehler@med.uni-heidelberg.de 
6 weeks. An association between fetal heart rate and behavioral inhibition has also been postulated. In accordance with these findings behaviorally inhibited children were found to display elevated levels of salivary cortisol. A right frontal EEG asymmetry has also been shown to be associated with inhibited behavior [11]. In an independent line of research, studies on infants of postnatally depressed mothers have rendered similar results with regard to infant psychophysiology: infants and toddlers of postnatally depressed mothers have been shown to display the right frontal EEG asymmetry pattern [12]. Furthermore, as reported for inhibited children, infants of depressed mothers also have elevated salivary cortisol levels and a lower cardiac vagal tone [13].

These striking similarities between infants of postnatally depressed mothers and inhibited children give reason to postulate an association between childhood behavioral inhibition and maternal postpartum depression.

Previous investigations concerning behavioral inhibition in children in relation to parental psychopathology have focused primarily on 2- to 7-year-old children [14] and found a higher incidence of parental anxiety disorder in inhibited children. No previous research has examined behavioral inhibition in relation to nonclinical maternal psychopathology.

In a comparative study on mothers with panic disorders and their infants no difference in infant reactivity or toddlers' behavioral inhibition was found between children of panic disorder and control mothers [15].

To date, no study has longitudinally evaluated the effect of maternal subclinical depressive symptoms and general psychopathology during the first year of life on toddlers' behavioral inhibition.

It seems crucial to address this question, however, since behavioral inhibition has demonstrated longitudinal stability frequently enough to be regarded as a considerable risk factor for emotional development in childhood [16]. If maternal psychopathology might be identified as a risk factor for toddler behavioral inhibition, preventive strategies should be developed targeting the maternal emotional state during the first year of the infant's life.

\section{Methods}

\section{Participants}

The sample of this study consisted of a volunteer sample of healthy Caucasian mothers and their infants after singleton pregnancies recruited in the four major local obstetric units, who attract a mixed urban and rural population. Eligibility criteria were full-term deliveries and infant weight above 2,500 g, Apgar scores $>7$ and good health of the baby as documented by the first, second and third postnatal examination. Exclusion criteria were inability to speak and read the German language as well as the use of drugs or medications posing a risk to the fetus and/or excessive smoking ( $>5$ cigarettes/day) or alcohol consumption during pregnancy. Written informed consent was obtained from all participants.

Power calculation had determined a sample size of 100 mother-infant pairs. Out of 114 mothers who decided to take part in the study, 13 dropped out before study inclusion so that 102 mother-infant pairs were finally included in the study. After study inclusion 1 mother decided not to continue with the study after the first assessment so that 101 mother-infant pairs completed the study.

\section{Study Design}

The subjects were seen in the laboratory when the infant was 2 weeks, 6 weeks and 4 and 14 months of age. Socioeconomic status, pre- and perinatal data were documented at the first assessment, and infant health status was assessed at every visit. Life events, medical pregnancy complications and maternal and paternal personality were assessed at 2 weeks postnatal age, maternal general psychopathology was measured at 2 weeks, 2, 4 and 14 months postnatal age. Postpartum depression was measured at 4 months postnatal age. Behavioral inhibition was assessed in a laboratory procedure at the age of 14 months. Mothers brought their infants to the laboratory in the daytime, when their infant was alert, fed and rested.

\section{Measures}

Revised 90-Item Symptom Checklist. During each session maternal psychopathology was measured via the German version [17] of the revised 90-item Symptom Checklist (SCL-90R) [18] consisting of the scales somatization, depression, compulsions, general anxiety, social anxiety, phobic anxiety, psychoticism, paranoia, hostility and global severity index.

Edinburgh Postnatal Depression Scale. Symptoms of maternal depression were assessed by the Edinburgh Postnatal Depression Scale (EPDS) [19, 20], which is a screening instrument for postnatal depression. It is an internationally accepted 10 -item self-report measure of the specific symptomatology of postnatal depression. The analysis of the sensitivity and the specificity [21] of the EPDS provides a cutoff score of 9 (sensibility: 0.88; specificity: $0.50)$ as predictive of postpartum depression; for this cutoff score, the type I error is low (5.8\%), the type II error is higher (18.9\%).

Behavioral Inhibition at 14 Months. Behavioral inhibition was assessed according to the procedures previously described [22, 23]. Mothers and toddlers visited the laboratory in the daytime, when the child was fed and rested. Each dyad entered an unfamiliar room containing a low table and one large and two small chairs. For each dyad the visit began with the measurement of the toddler's ECG. The toddlers sat in a high chair and had 3 ECG electrodes placed on their chests. For trial 1, a large metal wheel was placed on a table directly in front of the child's seat and rotated 6 times for $30 \mathrm{~s}$, filled with an increasing number of rattling colored objects $(0,1,2,3,4,0)$. For the next trial, the child was asked to dunk his finger in small cups containing water, red liquid and black liquid. Trial 3 required the children to accept a drop of water, sweet and sour liquid on their tongues. After that, 2 differ- 
ent rotating toys were placed in front of the child with the examiner speaking friendly and unfriendly syllables. The next trial involved a second examiner entering the room with a white coat and a face mask, placing herself at $30 \mathrm{~cm}$ in front of the child and speaking a short sentence to the child. Trial 5 consisted in a puppet theater with a friendly and an unfriendly puppet speaking mutually to the child. Next, an unfamiliar woman entered the room. She sat quietly for $1 \mathrm{~min}$, then (if the toddler had not yet approached) encouraged the child to join her in play. After a third minute, she left, returning with a large toy robot that moved and made noise. The experimenter did not say anything for $30 \mathrm{~s}$ and then invited the child to play with the robot for $1 \mathrm{~min}$. For the last episode, the experimenter returned with a dark cloth over head and shoulders, sitting for 1 min quietly and then asking the child to join her. At the end a separation-reunion procedure was conducted with the mother leaving the room for $30 \mathrm{~s}$ and the examiner staying in the room comforting the child if necessary. The whole procedure was videotaped.

Inhibition Coding. The infant's behavior was coded by at least 2 raters independently observing the videotaped session. Each child's individual fear score was composed of the sum of the frequency of the following aspects of behavior: failure to follow instruction for the finger dunking and liquid tasting episodes, failure to approach for the stranger episodes and crying/fretting in each of the episodes. Interrater reliability was good with an intraclass correlation of 0.92 .

\section{Potential Covariates}

Maternal and Paternal Personality Characteristics. Maternal and paternal personality characteristics were assessed at 2 weeks by the German version [24] of the NEO Five-Factor Inventory [25], a 60 -item questionnaire assessing 5 dimensions of personality (extroversion, openness, conscientiousness, agreeableness and neuroticism).

Life Events in Pregnancy and during the First 14 Months. For the assessment of life events in pregnancy, a standardized interview, the Leipzig Event and Stressors Inventory [26], was conducted 2 weeks postnatally and at 14 months of child age. This 45 -min interview is a valid measure for the assessment of life events in the last 9 months preceding the interview. It comprises 50 major and minor stressors and hassles resulting in a sum score of stressors according to the Lazarus stress concept. The instrument has a test-retest reliability of 0.89 .

\section{Results}

Sample

The women were between the ages of 19 and 45 years (mean $=33.3$ years), mean infant weight was $3,497 \mathrm{~g}$, ranging from 2,520 to $4,500 \mathrm{~g} ; 44.6 \%$ of the infants were girls, $51.5 \%$ were firstborn; $35.6 \%$ had 1 sibling, $12.9 \%$ had 2 or more siblings; $55.5 \%$ of the mothers had at least a college degree. All mothers were in a partnership with the infant's father. The relationship between sociodemographic variables and the children's fear score is presented in table 1 .
Table 1. Mean and SD of fear score for sociodemographic variables

\begin{tabular}{lccccc}
\hline & Mean & SD & Number & Percent & $\mathrm{p}$ \\
\hline Gender & & & & & 0.289 \\
$\quad$ Male & 2.95 & 2.19 & 56 & 55.4 & \\
$\quad$ Female & 3.42 & 2.27 & 45 & 44.6 & \\
Maternal education & & & & & 0.910 \\
$\quad$ High school & 3.08 & 2.59 & 25 & 24.6 & \\
$\quad$ College & 3.35 & 2.34 & 20 & 19.8 & \\
$\quad$ University degree & 3.12 & 2.04 & 56 & 55.6 & \\
Number of siblings & & & & & 0.300 \\
$\quad$ 0 & 2.82 & 2.01 & 52 & 51.5 & \\
$\quad$ 1 and more & 3.55 & 2.47 & 36 & 35.6 & \\
$\quad 3.38$ & 2.92 & 13 & 12.9 & \\
\hline Total sample & 3.16 & 2.23 & 101 & 100 & \\
\hline
\end{tabular}

The $\mathrm{p}$ value is the result of an analysis of variance relating the fear score as dependent variable with sociodemographic categories.

Table 2. Mean and SD of fear score for pre-, peri- and postnatal complications

\begin{tabular}{|c|c|c|c|c|c|}
\hline & Mean & SD & Number & Percent & $\mathrm{p}$ \\
\hline \multicolumn{5}{|c|}{ Prenatal complications } & 0.020 \\
\hline Yes & 3.36 & 1.85 & 72 & 71.8 & \\
\hline No & 2.65 & 2.34 & 29 & 28.2 & \\
\hline \multicolumn{5}{|c|}{ Perinatal complications } & 0.928 \\
\hline Yes & 3.14 & 2.25 & 75 & 74.6 & \\
\hline No & 3.19 & 2.20 & 26 & 25.4 & \\
\hline \multicolumn{5}{|c|}{ Postnatal complications } & 0.043 \\
\hline Yes & 4.18 & 2.16 & 16 & 15.5 & \\
\hline No & 2.96 & 2.20 & 85 & 84.5 & \\
\hline Total sample & 3.16 & 2.23 & 101 & 100 & \\
\hline
\end{tabular}

The $p$ values are the results of an analysis of variance relating the fear score as dependent variable with sociodemographic variables.

\section{Covariates}

Infant gender or maternal education were not significantly related to the toddler's fear score (table 1). Pre- and postnatal medical complications were not associated with children's fear, but for perinatal complications a significant relation was found. There was a tendency for perinatal complication to correlate with postnatal depression (table 2). As shown in table 3, neither life events during pregnancy nor life events during the infant's first 14 
Table 3. Means, SD of covariates and their correlation with child fear score

\begin{tabular}{lllrl}
\hline & Mean & SD & R & $\mathrm{p}$ \\
\hline Maternal personality & & & & \\
$\quad$ Neuroticism & 1.40 & 0.60 & 0.02 & 0.830 \\
$\quad$ Extroversion & 2.54 & 0.41 & -0.09 & 0.430 \\
$\quad$ Openness & 2.62 & 0.42 & 0.02 & 0.859 \\
$\quad$ Agreeableness & 2.84 & 0.43 & 0.03 & 0.762 \\
$\quad$ Conscientiousness & 2.95 & 0.45 & 0.27 & 0.797 \\
Paternal personality & & & & \\
$\quad$ Neuroticism & 1.16 & 0.54 & 0.07 & 0.57 \\
$\quad$ Extroversion & 2.41 & 0.48 & 0.11 & 0.35 \\
$\quad$ Openness & 2.53 & 0.52 & 0.04 & 0.68 \\
$\quad$ Agreeableness & 2.58 & 0.44 & 0.15 & 0.16 \\
$\quad$ Conscientiousness & 2.89 & 0.53 & 0.10 & 0.92 \\
Life events & & & & \\
$\quad$ Prenatal & 4.22 & 2.37 & 0.079 & 0.44 \\
Postnatal & 16.1 & 6.01 & 0.015 & 0.89 \\
\hline
\end{tabular}

$\mathrm{R}=$ Correlation coefficient or partial correlation coefficient in case of multiple regression for personality.

months showed any association with toddlers' behavioral inhibition at 14 months. The 'Big Five' maternal $[\mathrm{F}(5,95)=0.2, \mathrm{r}=0.96]$ and paternal $[\mathrm{F}(5,93)=0.8$, $\mathrm{r}=0.2]$ personality characteristics had no relation to childrens' behavioral inhibition at 14 months either, as shown in table 3.

\section{Edinburgh Postnatal Depression Scale}

The hypothesis that maternal postnatal depression was related to the infant's fear score was tested with a 2sample t test with equal variances. Eight mothers were above the cutoff with an EPDS score of 10 or higher, whereas 92 mothers were not. The children of these mothers had a mean fear score of $4.9(\mathrm{SD}=0.83)$, whereas the children of other mothers had a mean fear score of 2.8 $(\mathrm{SD}=0.22)$. The difference was significant ( $\mathrm{t}$ test: $\mathrm{t}=$ -2.16 , d.f. $=99, \mathrm{p}=0.01)$. The children of mothers with postnatal depression at 4 months postnatal age had a significantly higher fear score at 14 months.

\section{Revised 90-Item Symptom Checklist}

Of the 9 subscales of the SCL-90R (table 4), only depression $[\mathrm{F}(4,93)=2.95, \mathrm{p}=0.02]$ and general anxiety $[\mathrm{F}(4,93)=2.63, \mathrm{p}=0.0392]$ were predictive of the child's fear score at 14 months. On closer inspection with partial correlations, maternal depression at 6 weeks and 4 months and general anxiety at 6 weeks were the most important predictors for toddlers' fear scores at 14 months. Mothers with low depression and anxiety at 6 weeks and high depression at 4 months after birth had children with significantly higher fear scores than women with decreasing or stable depressive symptomatology between 6 weeks and 4 months. These data indicate that a specific type of depression with an onset and a steep increase between 6 weeks and 4 months postnatally is related to behavioral inhibition in the offspring.

\section{Discussion}

The data presented above indicate an association between maternal emotional state, especially postnatal depression in the first year of life, and infant development. This finding seems consistent with the fact that infants of postnatally depressed mothers and behaviorally inhibited children share a common psychophysiological background $[12,13]$. These data confirm observations of a recent community-based longitudinal study that maternal depression correlates with infant withdrawal and fear, assessed with a different methodology [27].

This study adds to the existing knowledge about postnatal maternal mood and infant emotional development insofar as maternal mood was monitored at several time points during the first 14 months. This close monitoring resulted in a better understanding of the relationship between the course of maternal depression and childhood fear, as the data presented above show that a steep increase in maternal depressive symptomatology from low depression to high depression between 6 weeks and 4 months is the strongest risk factor for the development of an extremely fearful disposition in the offspring. Behavioral inhibition in children of mothers who score above the cutoff for postpartum depression at 4 months in the EPDS is considerably elevated. Anxiety at 6 weeks was found to be predictive of behavioral inhibition as well, although the correlation was lower and is thought to be due to the frequent comorbidity of depression and anxiety [28].

These data also warrant the conclusion that late-onset postpartum depression might be a clinical category that is etiologically distinct from a transient depressive symptomatology occurring shortly after birth, as the impact on child emotional development is very different. Whereas postpartum blues-like symptoms might be more prominent in women with increased vulnerability to hormonal changes, depression occurring at 4 months might be less related to hormonal changes and probably due to a 
Table 4. Means and SD of maternal psychopathology and correlation with fear score

\begin{tabular}{|c|c|c|c|c|c|c|c|c|}
\hline & \multicolumn{2}{|l|}{2 weeks } & \multicolumn{2}{|l|}{6 weeks } & \multicolumn{2}{|l|}{4 months } & \multicolumn{2}{|l|}{14 months } \\
\hline & mean & $\mathrm{r}$ & mean & $\mathrm{r}$ & mean & $\mathrm{r}$ & mean & $\mathrm{r}$ \\
\hline Somatization & $0.41(0.37)$ & 0.11 & $0.29(0.28)$ & 0.27 & $0.28(0.30)$ & -0.19 & $0.30(0.40)$ & 0.01 \\
\hline Compulsions & $0.36(0.37)$ & 0.05 & $0.30(0.42)$ & -0.20 & $0.30(0.40)$ & 0.40 & $0.28(0.33)$ & 0.02 \\
\hline Social anxiety & $0.29(0.32)$ & 0.01 & $0.25(0.32)$ & -0.17 & $0.25(0.38)$ & 0.29 & $0.25(0.33)$ & -0.09 \\
\hline Depression & $0.42(0.34)$ & 0.10 & $0.33(0.29)$ & -0.34 & $0.31(0.35)$ & 0.37 & $0.29(0.34)$ & 0.02 \\
\hline General anxiety & $0.20(0.25)$ & 0.11 & $0.13(0.20)$ & -0.35 & $0.13(0.24)$ & 0.18 & $0.16(0.27)$ & 0.23 \\
\hline Aggression & $0.40(0.33)$ & 0.21 & $0.31(0.33)$ & -0.11 & $0.22(0.25)$ & 0.26 & $0.30(0.35)$ & -0.09 \\
\hline Phobic anxiety & $0.10(0.18)$ & 0.17 & $0.10(0.10)$ & -0.09 & $0.04(0.10)$ & 0.09 & $0.05(0.13)$ & 0.02 \\
\hline Paranoia & $0.22(0.36)$ & 0.06 & $0.17(0.36)$ & -0.17 & $0.21(0.38)$ & 0.12 & $0.25(0.41)$ & 0.17 \\
\hline Psychoticism & $0.60(0.11)$ & -0.08 & $0.04(0.11)$ & -0.08 & $0.05(0.15)$ & 0.38 & $0.07(0.17)$ & 0.01 \\
\hline GSI & $0.30(0.24)$ & 0.08 & $0.22(0.22)$ & -0.39 & $0.22(0.24)$ & 0.46 & $0.24(0.26)$ & 0.04 \\
\hline
\end{tabular}

$\mathrm{r}=$ Partial correlation; GSI = Global Severity Index. Figures in parentheses indicate SD.

different genetic mechanism, one that might be underlying the child's anxiety disposition as well.

In order to clarify whether adequate diagnosis and treatment of maternal depression in the first year of life can prevent the development of early childhood inhibition or whether this association is completely genetically determined, further studies are of immediate relevance.

Evidence for a genetic influence on behavioral inhibition has been provided [9] as described above [4]. Nevertheless, one other aspect is not ruled out by the findings presented above: since this effect was not mediated by maternal personality, it might be postulated that maternal depression results in an altered interactional style, as previously described [29], causing infant inhibition and anxiety to rise. In fact, postnatally depressed mothers have been shown to be less sensitive than control mothers when interacting with their children [30]. Previous research has suggested that less parental sensitivity might contribute to later anxiety disorders by influencing the infant-parent attachment relationship. Children who have experienced less parental sensitivity early in life are at greater risk for developing insecure attachment relationships [31], and toddlers with insecure attachment relationships are at higher risk for developing anxiety disorders later in childhood and adolescence [16]. Less parental sensitivity and more parental anger could thus promote anxiety disorders by undermining the child's sense of security and competence [32].

The frequency of postnatal depression in our sample (about 8\%) was low, as compared to other populations [21]. This might probably be due to the socioeconomic status of our sample that was typical of a small university town with a large academic population. Given the usual prevalence of about $15 \%$ of postpartum depression, the association with altered child psychophysiological and emotional development becomes even more relevant. None of the mothers in this study was clinically diagnosed or treated for depression. Since even these - usually unrecognized - depressive reactions are associated with a significantly higher fear score of the child at 14 months, efforts should be intensified to investigate the background of this potentially harmful relation between maternal and child psychopathology.

The impact of clinical maternal depression on child development has frequently been examined in clinical populations and was found to be highly relevant [33-35]. Therefore it seems possible that even undiscovered maternal depression can - during a period of heightened cerebral plasticity such as the first year of life - lead to longlasting alterations of child emotional development as indicated by elevated levels of behavioral inhibition. This discovery in a community-based sample is highly relevant, since we found in our upper middle class sample that depression was never clinically noticed, but nevertheless posed an increased risk for child development. Therefore, our data underline an immediate relevance of detection of undiscovered maternal postnatal depression for infant emotional development. 


\section{Limitations}

The sample was community based as it is was designed to screen for an impact of maternal psychopathology in the first year of life on behavioral inhibition. It was not specifically designed for comparing infants of postnatally depressed mothers with infants of control mothers. It can be expected, though, that the findings reported above would be much more pronounced in a control group design, including mothers with clinical levels of depression.

Furthermore, the DSM diagnosis of postnatal depression has not been confirmed by a clinical interview. Nonetheless, clinical relevance of the postulated findings should give rise to further studies with a case-control design. Also, it should be investigated whether treatment of postnatal depression might alter the association between child inhibition and maternal depression or not, as this might point to a more interactional versus a more genetic mode of transmission.

\section{Clinical Relevance}

This study is clinically highly relevant for three aspects.

First, the data point to a possible effect of maternal mood on the infants' emotional development in the first 14 months of life. If these findings were confirmed, this knowledge could be used to design preventive programs targeting maternal emotional well-being especially in the first year of a child's life.

Given even higher incidences of postnatal depression in other samples, the association reported here might be of even higher clinical relevance for the prevention of childhood emotional disorders in at-risk populations.

Second, these results indicate that even maternal depression in mothers who do not seek treatment and otherwise would go undiscovered has an impact on child emotional development. Therefore, the data suggest the implementation of preventive programs targeting maternal emotional well-being in the first postnatal year in the general - not clinical - population.

Third, if the relationship between behavioral inhibition and maternal depression can be confirmed in a clinical population, this would underline the necessity for specification of preventive programs for children of postnatally depressed mothers. As the data indicate a specific risk for anxiety disorder in this population, intervention programs should specifically target prevention of chronic shyness and social phobia in these children.

\section{Acknowledgments}

We thank the participating obstetric hospitals for their support. We also thank Oliver Moehler for his help in establishing the experimental procedures. This research was funded by the German Research Foundation (MO 978/1-1/2).

\section{References}

1 Kagan J, Reznick S, Snidman N: Biological bases of childhood shyness. Science 1988; 240:167-171.

-2 Aksan N, Kochanska G: Links between systems of inhibition from infancy to preschool years. Child Dev 2004;75:1477-1490.

-3 Kagan J, Snidman N: Early childhood predictors of adult anxiety disorders. Biol Psychiatry 1999;46:1536-1541.

4 Biedermann JF, Bolduc-Murphy EA, Faraone SV, Chaloff J, Hirschfeld DR, Kagan J: A 3-year follow-up of children with and without behavioral inhibition. Child Adolesc Psychiatry 1993;32:814-821.

5 Biedermann JF, Hirshfeld DR, Faraone SV, Bolduc EA, Gersten M, Meminger SA, Kagan J, Reznick S: Psychiatric correlates of behavioral inhibition in young children of parents with and without psychiatric disorders. Arch Gen Psychiatry 1990;47:21-26.
-6 Hirshfeld DR, Rosenbaum JF, Biederman J, Bolduc EA, Faraone SV, Snidman N, Reznick JS, Kagan J: Stable behavioral inhibition and its association with anxiety disorder. J Am Acad Child Adolesc Psychiatry 1992;31:103111.

-7 Rubin KH, Hastings P, Stewart S, Henderson $\mathrm{H}$, Chen X: The consistency and concomitants of inhibition: some of the children, all of the time. Child Dev 1997;68:467-483.

$>8$ Smoller J, Rosenbaum J, Biederman J, Suesswein L, Kagan J, Snidman N, Laird N, Tsuang MT, Faraone SV, Schwarz A, Slaugenhapt SA: Genetic association analysis of behavioral inhibition using candidate loci from mouse models. Am J Med Genet 2001; 105:226-235.
-9 Smoller J, Rosenbaum J, Biederman J, Kennedy J, Dai D, Racette SR, Laird N, Kagan J, Snidman N, Hirshfeld-Becker D, Tsuang MT, Sklar PB, Slaugenhapt SA: Association of a genetic marker at the corticotropin-releasing hormone locus with behavioral inhibition. Biol Psychiatry 2003;54:1376-1381

10 Kagan J, Reznik JS, Gibbons J: Inhibited and uninhibited types of children. Child Dev 1989;60:838-845.

11 Kagan J, Reznick JS, Snidman N: The physiology and psychology of behavioral inhibition in children. Child Dev 1987;58:14591473.

12 Jones NA, Field T, Davalos M, Pickens J: EEG stability in infants/children of depressed mothers. Child Psychiatry Hum Dev 1997; 28:59-70.

$>13$ Field T: Infants of depressed mothers. Dev Psychopathol 1992;4:49-66. 
14 Rosenbaum JF, Biedermann J, Bolduc EA, Hirshfeld D, Faraone SV, Kagan J: Comorbidity of parental anxiety disorders as risk for childhood-onset anxiety in inhibited children. Am J Psychiatry 1992;149:475481.

-15 Warren S, Gunnar MR, Kagan J, Anders TF, Simmens SJ, Rones M, Wease S, Aron E, Dahl RE, Sroufe LA: Maternal panic disorder: infant temperament, neurophysiology and parenting behaviors. J Am Acad Child Adolesc Psychiatry 2003;42:814-825.

-16 Biederman J, Hirshfeld-Becker DR, Rosenbaum JF, Herot C, Friedman D, Snidman N, Kagan J, Faraone SV: Further evidence of association between behavioral inhibition and social anxiety in children. Am J Psychiatry 2001;158:1673-1679.

17 Franke G: Eine weitere Überprüfung der Symptom-Checkliste (SCL-90R) als Forschungsinstrument. Diagnostica 1992;38: 160-167.

18 Derogatis LR, Lipman RS, Covi L: SCL-90: an outpatient psychiatric rating scale - Preliminary report. Psychopharmacol Bull 1973;9:13-28.

-19 Bergant A, Nguyen T, Moser R, Ulmer H: Prevalence of depressive disorder in early puerperium. Gynäkol Geburtshilfliche Rundsch 1998;38:232-237.
20 Cox JL, Kolden JM, Sagovsky R: Detection of postnatal depression: development of Edinburgh Postnatal Scale. Br J Psychiatry 1987; 150:782-786.

21 Teissedre F, Chabrol H: A study of the Edinburgh Postnatal Depression Scale (EPDS) on 859 mothers: detection of mothers at risk for postpartum depression. Encéphale 2004;30 376-381.

22 Kagan J: Galen's Prophecy. New York, Basic Books, Westview Press, 1994, pp 215-241.

23 Moehler E, Brunner R, Wiebel A, Kaufmann C, Resch F: Association of behavioral inhibition with hair pigmentation in a European sample. Biol Psychol 2006;72:344-346.

24 Borkenau P, OstendorfF: Untersuchung zum Fünf-Faktorenmodell der Persönlichkeit und seiner diagnostischen Erfassung. Z Diff Diagn Psychol 1989;10:239-251.

25 Costa PT, McCrae RR: The NEO Personality Inventory: Manual Form $\mathrm{S}$ and Form $\mathrm{R}$. Odessa, Psychological Assessment Resources, 1985.

26 Richter V, Guthke J: Das Leipziger Ereignisund Belastungsinventar. Göttingen, Hogrefe, 1996.

27 Pauli-Pott U, Mertesacker B, Beckmann D: Predicting the development of infant emotionality from maternal characteristics. Dev Psychopathol 2004;16:19-42.

-28 Perfetti J, Clark R, Fillmore CM: Postpartum depression: identification, screening and treatment. WMJ 2004;103:56-63.
29 Reck C, Backenstrass M, Möhler E, Hunt A, Resch F, Mundt C: Mutter-Kind-Interaktion und postpartale Depression: Theorie und Empirie im Überblick. Psychother Psychosom Med Psychol 2001;6:171-186.

30 Campbell S, Brownell C, Hungerford A, Spieker S, Mohan R, Blessing J: The course of maternal depressive symptoms and maternal sensitivity as predictors of attachment security at 36 months. Dev Psychopathol 2004; 16:231-252.

31 Ainsworth MD, Bell SM: Infant crying and maternal responsiveness: a rejoinder to Gewirtz and Boyd. Child Dev 1977;48:12081216.

32 Oyen A, Landy S, Hilburn-Cobb C: Maternal attachment and sensitivity in an at-risk sample. Attach Hum Dev 2000;2:203-217.

33 Lee CM, Gotlib IH: Maternal depression and child adjustment: a longitudinal analysis. J Abnorm Psychol 1989;1:78-85.

34 Milgrom J, Westley DT, McCloud PI: Do infants of depressed mothers cry more than other infants? J Paediatr Child Health 1995; 31:218-221.

35 Murray L, Hipwell A, Hooper R, Stein A, Cooper P: The cognitive development of 5 year-old children of postnatally depressed mothers. J Child Psychol Psychiatry Allied Discip 1996;37:927-935. 